\title{
A salinity and sulfate manipulation of hypersaline microbial mats reveals stasis in the cyanobacterial community structure
}

\author{
Stefan J Green ${ }^{1,2}$, Cameron Blackford ${ }^{2,4}$, Patricia Bucki ${ }^{3}$, Linda L Jahnke ${ }^{2}$ \\ and Lee Prufert-Bebout ${ }^{2}$ \\ ${ }^{1}$ SETI Institute, Mountain View, CA, USA ${ }^{2}$ Exobiology Branch, NASA Ames Research Center, Moffett Field, \\ CA, USA and ${ }^{3}$ The Agricultural Research Organization of Israel, The Volcani Center, Bet-Dagan, Israel
}

\begin{abstract}
The cyanobacterial community structure and composition of hypersaline mats were characterized in an experiment in which native salinity and sulfate levels were modified. Over the course of approximately 1 year, microbial mats collected from Guerrero Negro (Baja, California Sur, Mexico) were equilibrated to lowered salinity (to 35 p.p.t.) and lowered sulfate (below $1 \mathrm{~mm}$ ) conditions. The structure and composition of the cyanobacterial community in the top $5 \mathrm{~mm}$ of these mats were examined using a multifaceted cultivation-independent molecular approach. Overall, the relative abundance of cyanobacteria-roughly $20 \%$ of the total bacterial community, as assayed with a PCRbased methodology-was not significantly affected by these manipulations. Furthermore, the mat cyanobacterial community was only modestly influenced by the dramatic changes in sulfate and salinity, and the dominant cyanobacteria were unaffected. Community composition analyses confirmed the dominant presence of the cosmopolitan cyanobacterium Microcoleus chthonoplastes, but also revealed the dominance of another Oscillatorian cyanobacterial group, also detected in other hypersaline microbial mats. Cyanobacterial populations increasing in relative abundance under the modified salinity and sulfate conditions were found to be most closely related to other hypersaline microbial mat organisms, suggesting that the development of these mats under native conditions precludes the development of organisms better suited to the less restrictive experimental conditions. These results also indicate that within a significant range of salinity and sulfate concentrations, the cyanobacterial community is remarkably stable.
\end{abstract}

The ISME Journal (2008) 2, 457-470; doi:10.1038/ismej.2008.6; published online 21 February 2008

Subject Category: microbial population and community ecology

Keywords: cyanobacteria; Microcoleus chthonoplastes; Oscillatoriales; salinity; sulfate

\section{Introduction}

Preserved laminated communities, morphologically analogous to modern microbial mats, have been found in the sedimentary record dating back 3.5 billion years (Awramik, 1984). These ancient laminated microbial ecosystems developed under significantly different environmental conditions than do modern mats, as low oceanic and atmospheric oxygen concentrations, and low oceanic sulfate concentrations have been inferred from geological data (Canfield and Teske, 1996; Canfield et al., 2000; Habicht et al., 2002; Pavlov and Kasting, 2002). In Earth's modern environment, microbial mats are restricted to environments where metazoal grazing is limited,

Correspondence: L Prufert-Bebout, Exobiology Branch, NASA Ames Research Center, MS 239-4, Moffett Field, CA 94035, USA. E-mail: Leslie.E.Bebout@nasa.gov

${ }^{4}$ Current address: Pioneer Hi-Bred International, El Cerrito, CA, USA

Received 9 November 2007; revised 30 December 2007; accepted 3 January 2008; published online 21 February 2008 generally due to 'extreme' environmental conditions (Awramik, 1984). The thickest and most extensively studied microbial mats develop under moderately hypersaline conditions (for example, 85-100 p.p.t.), exhibiting extremely high rates of primary production and organic recycling (for example, Krumbein et al., 1977; Jorgensen, 1982; Aizenshtat et al., 1984; Canfield and Des Marais, 1991, 1994).

The top few millimeters of these microbial mats is a highly dynamic physical and chemical environment controlled by the interaction of the physical and biological elements of the system. In most hypersaline mat systems cyanobacteria are the major mat-building microorganisms, producing mucopolysaccharide sheaths that are partially responsible for the thick, laminated texture of the microbial mat and are also the largest contributors to primary production (Stal et al., 1985; D'Amelio et al., 1989; Stal, 1995). During the day, incident light is rapidly attenuated by the cyanobacteria, and the depletion of light wavelengths suitable for oxygenic photosynthesis, coupled with high rates of heterotrophic 
respiration, generates a dramatic oxygen chemocline a few millimeters below the surface (for example, Jorgensen et al., 1983; D’Amelio et al., 1989; Minz et al., 1999). Owing to the high respiratory activity and the absence of photosynthesis at night, the mats can become entirely anaerobic, with sulfide accumulating at the surface as a result of the activity of sulfate-reducing prokaryotes (for example, Revsbech et al., 1983; Frund and Cohen, 1992; Minz et al., 1999). Tolerances to high sulfide and high salinity appear to be major determinants for the success of cyanobacteria as primary producers in these systems (Cohen et al., 1986; Nübel et al., 2000). Microbial mat cyanobacteria exposed to high levels of sulfide during the diurnal cycle have evolved a variety of different responses to its toxicity. Some cyanobacteria have the capacity to use sulfide as an electron donor for anoxygenic photosynthesis (Cohen et al., 1986). The dominant hypersaline mat cyanobacterium Microcoleus chthonoplastes has been shown to have an oxygenic photosystem (photosystem II) highly resistant to sulfide, and the capacity to utilize sulfide as an electron donor for photosystem I (Jorgensen et al., 1986; de Wit and Van Gemerden, 1987).

In part because the modern geographic distribution of microbial mats is limited to extreme environments, extrapolation to ancient microbial ecosystems can be difficult. To overcome some of these limitations, hypersaline microbial mats have been sampled and returned to a greenhouse facility at the NASA Ames Research Center (ARC) in Moffett Field (CA, USA) and maintained under experimentally modified conditions (Bebout et al., 2002, 2004; Kelley et al., 2006). Over the course of a year, salinity and sulfate concentrations were lowered significantly. In these experimental mat ecosystems, the effects of these manipulations on carbon cycling, including methanogenesis, have been previously explored (Kelley et al., 2006; Smith et al., 2008). We hypothesized that the experimental manipulations of salinity and sulfate concentrations would also significantly impact the cyanobacterial community structure. To examine this hypothesis, a multifaceted molecular approach was employed. These analyses revealed that the experimental manipulation only modestly impacted the cyanobacterial community structure. The predominant mat cyanobacteria, including M. chthonoplastes and a hypersaline microbial mat-specific group of uncultured filamentous Oscillatorian cyanobacteria, were essentially unaffected.

\section{Materials and methods} Maintenance of microbial mats and establishment of
experimental conditions

Microbial mats from salterns operated by the saltproducing company, Exportadora de Sal SA de CV, located in Guerrero Negro (Baja, California Sur,
Mexico) were sampled and returned to the NASA ARC in Moffett Field (CA, USA) (Kelley et al., 2006). The mat samples were taken from the Concentrating Area 4, which has a salinity of approximately 85 p.p.t. and a sulfate concentration of approximately $50 \mathrm{mM}$, and maintained in a series of flume systems in which the salinity and sulfate concentrations were experimentally modified. Two replicate flumes for each treatment were maintained for over 1 year (Porewater measurements were taken at 17 months after the beginning of the experiment, while overlying water measurements were taken routinely; Kelley et al., 2006; Smith et al., 2008). The four treatments include a high-salinity and high-sulfate treatment representing field conditions (85P), a lowered salinity treatment with sulfate (35P), a lowered sulfate and field salinity treatment (85M), and a lowered sulfate and salinity treatment (35M) (see Table 2; Kelley et al., 2006).

\section{Sampling and DNA extraction}

Sampling of microbial mats was performed at the start of the experiment ('T0'; 5 June 2003, 85P sample only), after 4.5 months of equilibration ('T1'; 24 October 2003; two samples per treatment) and after 11 months of equilibration ('T2'; 12 May 2004; six samples; two samples per treatment except for 85P). At each sampling, small vertical cores of the mats from two replicate flumes for each treatment were sampled and frozen. Genomic DNA was extracted from the $0-5 \mathrm{~mm}$ section of each mat core (50-100 mg per sample) using components of the UltraClean Soil DNA kit (Mo Bio Laboratories Inc., Carlsbad, CA, USA) with a modified extraction buffer (100 mM Tris-HCl, $\mathrm{pH} 8.0 ; 100 \mathrm{mM}$ potassium phosphate buffer $\mathrm{pH} 8.0 ; 1 \%$ hexadecyltrimethylammonium bromide; and $2 \%$ sodium dodecyl sulfate; Zhou et al., 1996). After bead beating, the samples were centrifuged briefly and concentrated potassium ethyl xanthogenate solution was added (Tillett and Neilan, 2000) to a final concentration of $800 \mathrm{~mm}$ ammonium acetate and 1\% potassium ethyl xanthogenate (Fluka, Buchs, Switzerland). After $2 \mathrm{~h}$ at $65{ }^{\circ} \mathrm{C}, 30 \mathrm{~min}$ on ice and centrifugation $(20000 \mathrm{~g})$, the supernatant was recovered and mixed with KCl to a final concentration of $0.5 \mathrm{M}$, incubated for $5 \mathrm{~min}$ and centrifuged again $(20000 \mathrm{~g})$. The supernatant was combined with $\mathrm{NaCl}$ (final concentration of $0.5 \mathrm{M}$ ) and ethanol for nucleic acid precipitation overnight at $-20^{\circ} \mathrm{C}$. The air-dried DNA pellet was dissolved in solution S3 and subject to silica binding, cleaning and elution stages of the Mo Bio kit.

Cyanobacterial community structure analysis

Genomic DNA extracted from mat samples was utilized for molecular analyses of bacterial and cyanobacterial community composition. Genomic DNA extracts were PCR amplified using general and specific primer sets, using the Biomix Red $(1.5 \mathrm{mM}$ $\mathrm{MgCl}_{2}$ ) PCR mix from Bioline USA Inc. (Randolph, 
Table 1 Sequences for primers targeting bacterial and cyanobacterial 16S rRNA genes used in this study

\begin{tabular}{|c|c|c|c|c|}
\hline Primer & Sequence $\left(5^{\prime} \rightarrow 3^{\prime}\right)^{\mathrm{a}}$ & $\begin{array}{l}16 S \text { rDNA location } \\
\text { (Escherichia coli numbering) }\end{array}$ & $\begin{array}{l}\text { Target } \\
\text { population }\end{array}$ & Source \\
\hline $8 \mathrm{~F}$ & AGAGTTTGATCMTGGCTCAG & $8-27$ & Bacteria & Lane (1991) \\
\hline $8 \mathrm{~F}(\mathrm{a})$ & AGAGTTTGATCCTGGCTCAG & $8-27$ & Bacteria & Lane (1991); Ley et al. (2006) \\
\hline $1391 \mathrm{R}$ & GACGGGCGGTGWGTRCA & $1407-1391$ & Universal & Lane (1991); Ley et al. (2006) \\
\hline $1492 \mathrm{R}$ & GGYTACCTTGTTACGACTT & $1510-1492$ & Bacteria & Lane (1991) \\
\hline $341 \mathrm{~F}^{\mathrm{b}}$ & CCTACGGGAGGCAGCAG & $341-357$ & Bacteria & Muyzer et al. (1993) \\
\hline 907R & CCGTCAATTCMTTTGAGTTT & $926-907$ & Bacteria & Muyzer and Smalla (1998) \\
\hline CYA359F & GGGGAATYTTCCGCAATGGG & $359-378$ & Cyanobacteria & Nübel et al. (1997) \\
\hline CYA781R ${ }^{\mathrm{c}}$ & $\begin{array}{l}\text { GACTACTGGGGTATCTAATCCCATT } \\
\text { GACTACAGGGGTATCTAATCCCTTT }\end{array}$ & $805-781$ & Cyanobacteria & Nübel et al. (1997) \\
\hline
\end{tabular}

${ }^{\mathrm{a} C o n v e n t i o n a l ~ n u c l e i c ~ a c i d ~ c o d e s ~ a r e ~ e m p l o y e d, ~ w i t h ~} \mathrm{M}=\mathrm{A}$ or $\mathrm{C}, \mathrm{Y}=\mathrm{T}$ or $\mathrm{C}, \mathrm{R}=\mathrm{A}$ or $\mathrm{G}$, and $\mathrm{W}=\mathrm{A}$ or $\mathrm{T}$.

bontains a 40 base GC-clamp attached to the 5' end, as follows: CGCCCGCCGCGCCCCGCGCCCGTCCCGCCGCCCCCGCCCG.

${ }^{\mathrm{c}}$ The reverse primer is an equimolar mixture of the two primer sequences listed.

MA, USA). Magnesium concentrations were adjusted by addition of sterile $\mathrm{MgCl}_{2}$ solution. In addition, $6.25 \mu \mathrm{g}$ (per $50 \mu \mathrm{l}$ ) bovine serum albumin (Roche Diagnostics, Mannheim, Germany) was added to each reaction. Each primer was added to a final concentration of $0.5 \mu \mathrm{M}$.

Initially, genomic DNA was PCR amplified with the cyanobacterial primers CYA359F and CYA781R (Table 1), as previously described (Nübel et al., 1997). These PCR products were subsequently analyzed by denaturing gradient gel electrophoresis (DGGE) using the Ingeny U-Phor system (Ingeny, Goes, The Netherlands; Muyzer et al., 1993). DGGE analyses were performed using the following ingredients and conditions: $1 \times$ TAE buffer ( $40 \mathrm{mM}$ Tris- $\mathrm{HCl}, 20 \mathrm{mM}$ acetic acid, $1 \mathrm{mM}$ EDTA (pH 8.3)) and 1-mm thick polyacrylamide gels (6\%). Gels contained a 30-70\% denaturant gradient and were electrophoresed for $17 \mathrm{~h}$ at $80 \mathrm{~V}$ and $60^{\circ} \mathrm{C}$. Gels were stained with GelStar nucleic acid stain (Biowhittaker Molecular Applications, Rockland, ME, USA) and photographed on a UV transillumination table $(302 \mathrm{~nm})$ with a Fotodyne Foto/Analyst Express digital imaging system (Hartland, WI, USA). DGGE gel images were further analyzed using the Fingerprint II software (Bio-Rad Laboratories, Hercules, CA, USA). Initially, densitometric curves were recovered from the gel images and used to normalize the banding patterns. Bands were identified using the Fingerprint II software, coupled with visual inspection, and pairwise similarity values of the banding patterns of each sample were calculated using the Dice similarity coefficient. The Dice similarity matrix was then used to generate dendograms using Ward's method and the unweighted pair group method using arithmetic averages, implemented within the Fingerprint II software. Identical dendogram topology was observed with Ward's and unweighted pair group method using arithmetic averages analyses.

Screening of bacterial 16S rRNA gene clone library Genomic DNA was PCR amplified with the general bacterial primers $8 \mathrm{~F}$ and1492R (Table 1), generating a nearly complete $16 \mathrm{~S}$ rRNA gene fragment. These reactions were conducted as described above, but with a final magnesium concentration of $4.0 \mathrm{mM}$, and an annealing temperature of $50{ }^{\circ} \mathrm{C}$. The resulting PCR products were used as templates for cloning reactions using the TOPO TA cloning kit (Invitrogen, Carlsbad, CA, USA), according to the manufacturer's instructions. Individual clones from the generated clone libraries were screened by colony PCR with the cyanobacteria-specific primer set CYA359F/CYA781R (Sigler et al., 2003). The PCR yield was checked by agarose gel electrophoresis, and clones were identified as containing cyanobacterial 16S rRNA gene sequences if a PCR band of approximately $470 \mathrm{bp}$ (including the 40 base GCclamp) was detected. Under the PCR conditions and high-plasmid concentrations employed, clones containing cyanobacterial sequences yielded extremely strong PCR yield with secondary, nonspecific bands. Clones yielding weak or moderate intensity single band patterns never contained cyanobacterial sequences and were not counted as such in the clone library analysis. Verification of this screening methodology was performed by sequence analyses of a subset of the total number of clones that tested positively for the presence of cyanobacterial sequences by PCR amplification with cyanobacterial primers. In addition, a representative 96-well plate of bacterial 16S rRNA gene clones, previously screened with cyanobacterial primers, was fully sequenced.

Band excision and sequence analyses

Bacterial sequences recovered from the sequencing of the 96-well plate were classified with the ribosomal database project classifier (RDP; Cole et al., 2007) and with the basic local alignment search tool (BLAST) (NCBI; Altschul et al., 1997). A subset of cyanobacterial clones containing near fulllength cyanobacterial $16 \mathrm{~S}$ rRNA gene sequences were sequenced using primer sites contained on the TOPO TA vector. Where possible, sequences generated from multiple sequencing reactions from the 
same clone were assembled into a consensus sequence within the ARB software package prior to insertion into the full tree. To identify some cyanobacterial sequences, bands were excised from DGGE gels visualized on a UV transillumination table, as previously described (Green et al., 2004). DNA recovered from these bands was re-amplified using the cyanobacterial primers and compared to the environmental DGGE profile by an additional DGGE analysis. PCR products were then cleaned (GeneElute PCR Cleanup kit; Sigma-Aldrich, St Louis, MO, USA), cloned as above, screened by DGGE and submitted for sequence analyses. The sequence data set was tested for the presence of chimeric sequences by submission to the Bellerophon program (Huber et al., 2004) via the Greengenes website (http://greengenes.lbl.gov/); suspect sequences were removed from analyses. Cyanobacterial 16S rRNA gene sequences have been submitted to the GenBank database under accession numbers EU251079-EU251132 for those derived from the clone library and EU251133-EU251145 for those derived from excised DGGE bands.

Bacterial and cyanobacterial 16S rRNA gene sequences were aligned to known bacterial sequences using the 'Greengenes' 16S rRNA gene database and alignment tool (DeSantis et al., 2006a). Aligned sequences from this study and other studies employing cultivation-independent molecular analyses of microbial mat cyanobacteria (Nübel et al., 2000; Abed and Garcia-Pichel, 2001; Abed et al., 2002, 2006; Burns et al., 2004; Fourcans et al., 2004; Rothrock and Garcia-Pichel, 2005; Ley et al., 2006; Yannarell et al., 2006, 2007; unpublished sequences generated and submitted to the GenBank database with these accession numbers: DQ058831DQ058894, DQ423810-DQ424817, DQ154800-
DQ154900 and AM183934-AM183943) were imported into the Greengenes sequence database (DeSantis et al., 2006b) within the phylogenetic software package ARB (http://www.arb-home.de; Ludwig et al., 2004). Partial sequences, including those sequences recovered in this study, were inserted into the Greengenes 16S rRNA gene tree using the ARB parsimony option, employing a $50 \%$ maximum frequency cyanobacterial filter in which highly variable positions were ignored, while the overall topology of the tree was maintained.

\section{Results}

Full 16S rRNA gene clone library and screening

Genomic DNA from each sample was PCR amplified with the $8 F / 1492 \mathrm{R}$ bacterial $16 \mathrm{~S}$ rRNA gene primers targeting nearly the entire 16S rRNA gene. These PCR products were used to generate individual clone libraries, and from each sample approximately 30 clones were randomly selected for additional analysis. The total clone library consisted of 466 clones, from a total of 15 samples (Table 2). In total, roughly $20 \%$ of the bacterial clone library contained cyanobacterial sequences (Table 2). In individual clone libraries for each sample, the percentage of cyanobacterial clones ranged between $6.7 \%$ and $33 \%$ (Table 2). Regression analysis performed on these data using the LINEST function (Microsoft Excel; Microsoft Corporation, Redmond, WA, USA) did not reveal a significant effect of salinity or sulfate manipulation on the percent abundance of cyanobacteria within the clone libraries. A small negative effect on the relative abundance of cyanobacteria in the bacterial clone library was correlated with sampling time.

Table 2 Analysis of the relative abundance of cyanobacterial 16S rRNA gene clones within general bacterial 16S rRNA gene clone libraries of microbial mat samples

\begin{tabular}{|c|c|c|c|c|c|c|c|c|}
\hline \multirow{2}{*}{$\begin{array}{l}\text { Treatment } \\
\text { Units }\end{array}$} & \multirow{2}{*}{$\begin{array}{l}\text { Salinity } \\
\text { (p.p.t.) }\end{array}$} & \multirow{2}{*}{$\begin{array}{l}\text { Pore water } \\
\text { sulfate }^{\mathrm{a}} \\
\text { (mM) }\end{array}$} & \multirow{2}{*}{$\begin{array}{l}\text { Samples } \\
\text { (Number) }\end{array}$} & \multirow{2}{*}{$\begin{array}{c}\text { Clones, } \\
\text { total } \\
\text { (Number) }\end{array}$} & \multirow{2}{*}{$\begin{array}{c}\text { Clones, } \\
\text { cyanobacteria } \\
\text { (Number) }\end{array}$} & \multirow{2}{*}{$\begin{array}{c}\text { Clones, } \\
\text { cyanobacteria } \\
(\%)\end{array}$} & \multicolumn{2}{|c|}{ Range of replicate values } \\
\hline & & & & & & & Minimum (\%) & Maximum (\%) \\
\hline $85 \mathrm{P}$ & 85 & $51.7(1.0)$ & 3 & 92 & 25 & 27.2 & 20.0 & 33.3 \\
\hline $35 \mathrm{P}$ & 35 & $17.2(2.2)$ & 4 & 126 & 20 & 15.9 & 6.7 & 23.5 \\
\hline $85 \mathrm{M}$ & 85 & $0.9(0.2)$ & 4 & 122 & 21 & 17.2 & 15.6 & 20.0 \\
\hline $35 \mathrm{M}$ & 35 & $0.3(0.2)$ & 4 & 126 & 28 & 22.2 & 11.8 & 28.1 \\
\hline \multicolumn{9}{|l|}{ Composite analyses } \\
\hline High salinity & 85 & $0.3-51.7$ & 7 & 214 & 46 & 21.5 & 15.6 & 33.3 \\
\hline Low salinity & 35 & $0.3-51.7$ & 8 & 252 & 48 & 19.0 & 6.7 & 28.1 \\
\hline Unmodified sulfate & $35-85$ & $17.2-51.7$ & 7 & 218 & 45 & 20.6 & 6.7 & 33.3 \\
\hline Depleted sulfate & $35-85$ & $0.3-0.9$ & 8 & 248 & 49 & 19.8 & 11.8 & 28.1 \\
\hline Sampling time 0 & 85 & 51.7 & 1 & 32 & 9 & 28.1 & NA & NA \\
\hline Sampling time 1 & $35-85$ & $0.3-51.7$ & 8 & 246 & 50 & 20.3 & 8.0 & 33.3 \\
\hline Sampling time 2 & $35-85$ & $0.3-17.2$ & 6 & 188 & 35 & 18.6 & 6.7 & 26.7 \\
\hline All treatments & $35-85$ & $0.3-51.7$ & 15 & 466 & 94 & 20.2 & 6.7 & 33.3 \\
\hline
\end{tabular}

Abbreviation: NA, not applicable.

${ }^{a}$ Average concentration. Values in parentheses represent the standard deviation about the mean of eight samples. 
Table 3 Comparison of general bacterial 16S rRNA gene clone libraries generated in this study and a prior study of Guerrero Negro hypersaline microbial mats

\begin{tabular}{|c|c|c|c|c|}
\hline \multirow[t]{3}{*}{ Taxon } & \multicolumn{2}{|c|}{ This study $y^{\mathrm{a}, \mathrm{b}}$} & \multicolumn{2}{|c|}{ Ley et al. $(2006)^{\mathrm{b}}$} \\
\hline & \multicolumn{2}{|c|}{ 96-well plate $\mathrm{c}$} & \multicolumn{2}{|c|}{ Full library $(0-5 \mathrm{~mm})$} \\
\hline & Clones & Library, \% & Clones & Library, \% \\
\hline Cyanobacteria+plastids & 17 & 20.2 & 38 & 4.0 \\
\hline Proteobacteria & 13 & $15.5(19.4)$ & 211 & $22.2(23.2)$ \\
\hline Spirochetes & 13 & $15.5(19.4)$ & 53 & $5.6(5.8)$ \\
\hline Bacteroidetes & 13 & $15.5(19.4)$ & 168 & $17.7(18.4)$ \\
\hline Chloroflexi & 8 & 9.5 (11.9) & 210 & $22.1(23.1)$ \\
\hline Planctomycetes & 6 & $7.1(9)$ & 35 & $3.7(3.8)$ \\
\hline Verrucomicrobia & 3 & $3.6(4.5)$ & 39 & $4.1(4.3)$ \\
\hline GN14 & 3 & $3.6(4.5)$ & 2 & $0.2(0.2)$ \\
\hline Chlorobi & 2 & $2.4(3)$ & 1 & $0.1(0.1)$ \\
\hline Deinococcus-Thermus & 1 & $1.2(1.5)$ & 5 & $0.5(0.5)$ \\
\hline OD1 & 1 & $1.2(1.5)$ & 5 & $0.5(0.5)$ \\
\hline Actinobacteria & 1 & $1.2(1.5)$ & 1 & $0.1(0.1)$ \\
\hline Other & 3 & $3.6(4.5)$ & 181 & $19.1(19.9)$ \\
\hline Total & 84 & & 949 & \\
\hline
\end{tabular}

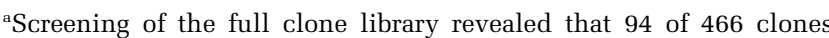
contained cyanobacterial sequences $(20.2 \%)$.

${ }^{\mathrm{b}}$ Percent abundance values in parentheses represent the abundance in the clone library with cyanobacterial sequences removed.

'Of 96 positions on the plate sent for screening, 6 positions were left empty and 6 clones did not contain inserts.

The efficacy of the screening methodology for rapid determination of cyanobacterial clones was verified by sequencing of a 96-well plate of clones using a primer targeting a site in the TOPO TA vector. These sequencing results are presented in Table 3 ('96-well plate') and were compared to the results of the clone library screening using cyanobacterial primers. Clones containing cyanobacterial sequences were predominant in the 96-well clone library (17 clones out of 84; 6 wells were left empty and 6 wells contained clones without inserts), and the clones detected as cyanobacteria in the clone-PCR analysis were confirmed as containing cyanobacterial sequences. A single false positive and a false negative were identified in this 96-well plate. Furthermore, in sequence analysis of clones identified as cyanobacteria, a total of 4 clones were revealed to be false positives, out of a test group of 287 clones. False negatives for the entire study could only be estimated from the 96-well plate sequencing, as only clones amplifying with the cyanobacterial primers were subsequently sequenced.

\section{Community composition analysis}

The effect of the environmental manipulations on the community composition and structure of the cyanobacterial populations in the mats was examined by PCR-denaturing gradient gel electrophoresis Genomic DNA from the mats was directly PCR amplified with cyanobacterial primers suitable for DGGE analysis. Replicate profiles from different flumes of the same treatment were found to be highly reproducible, and composite samples (combined PCR product from each sample of the same treatment) were used for further analysis. These composite samples were analyzed by DGGE (Figure 1). Two dominant cyanobacterial populations were observed in all samples, regardless of treatment. On the basis of multiple sequence analyses, the population represented by 'Band A' has $16 S$ rRNA genes almost identical to sequences from an uncultured group of cyanobacteria previously detected in Guerrero Negro and other microbial mats (Figure 2, 'Cluster 5'; for example, greater than 99\% similarity to a previously published Guerrero Negro cyanobacterial clone, DQ330753). On the basis of these analyses, Cluster 5 organisms can putatively be identified as filamentous, nonheterocystous cyanobacteria of the order Oscillatoriales. The second band, 'Band B' has a sequence almost identical (>99.5\% similarity) to that of M. chthonoplastes PCC 7420 (X70770) (Figures 1 and 2). In addition to these dominant populations other species were detected as well, with some variability in their presence. Four bands were excised (EB1-4) and cloned. Multiple clones generated from each band were sequenced (Figures 1 and 2). These included EB1, detected in the $35 \mathrm{M}$ (faintly at $\mathrm{T} 2$ ) and $85 \mathrm{M}$ (T1 and $\mathrm{T} 2$ ) treatments but not in the T0 sampling; EB2, detected in the 35P (T1 and faintly at T2), 85M (T1) and 35M (T1 and T2) treatments; EB3, detected in $85 \mathrm{M}(\mathrm{T} 2)$ treatment; and EB4, detected in 35M (T2) treatment. Sequences from clones representing band EB1 (EU251133-EU251136) were most closely related to sequences from cyanobacteria recovered from the Great Sippewissett Salt Marsh (97\% sequence identity to AJ007375). Sequences from clones representing band EB2 (EU251137-EU251140) were essentially identical to the sequence of a cyanobacterial clone recovered from the T2-35M treatment (EU251117), and were closely related to sequences from an uncultured microbial mat cyanobacterium (AY393855; Salins-de-Giraud, Camargue, France) and to Leptolyngbya sp PCC 8936 (96-97\% sequence identity; AM398800). Clones representing band EB3 (EU251141-EU251143) and EB4 (EU251144-EU251145) were almost identical to sequences derived from Bahamian mat cyanobacteria (for example, DQ140848 and DQ140794, respectively).

Although the two dominant cyanobacterial populations were present in all treatments and sampling points, cluster analysis of the cyanobacterial DGGE gel demonstrated shifts in the cyanobacterial community associated with sampling time and with treatment (Figure 1). Replicates of the control mat at the start of the experiment (T0-85P) were most similar to each other (node 'a'; Figure 1b) and divergent from the other samples. The cluster analysis also revealed that all the $\mathrm{T} 1$ samples, excepting the control (85P) treatment, were highly similar and clustered together (node ' $b$ '; Figure 1b). In all these samples, the population represented by the band EB3 was present. In addition, the cluster analysis indicated that the two low-sulfate treatments sampled at the second experimental sampling 

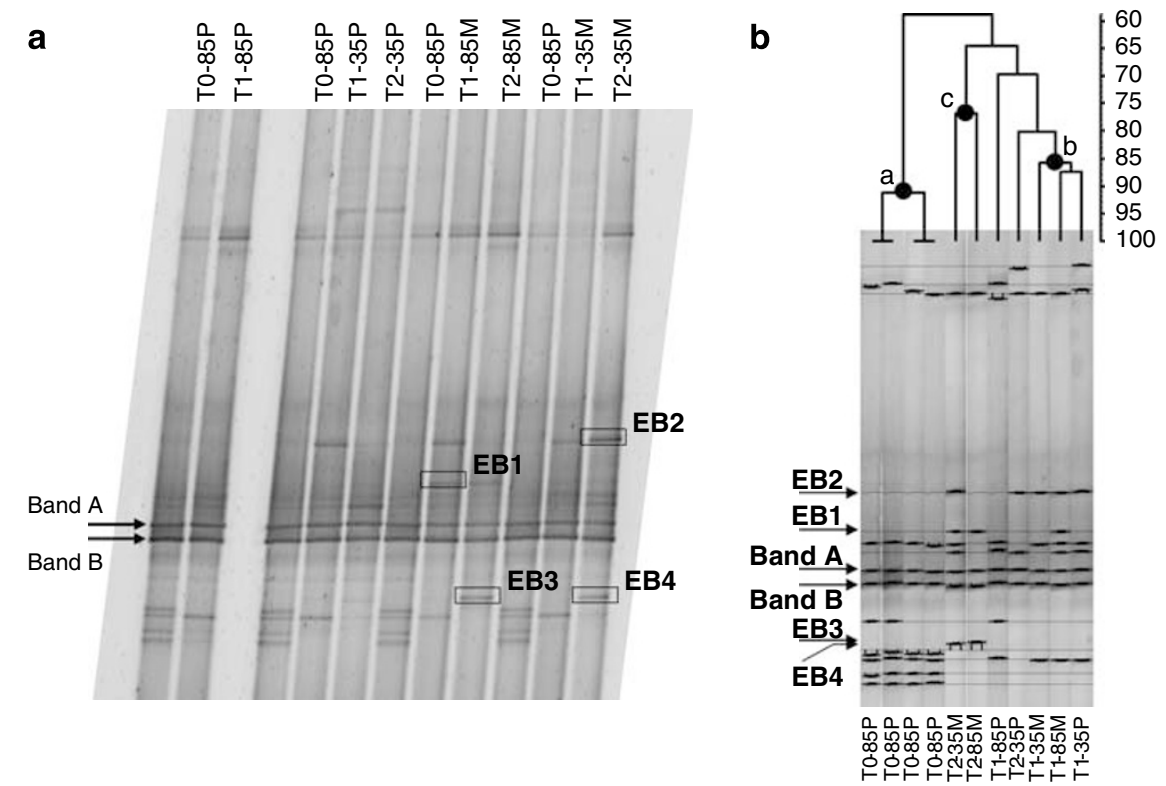

Figure 1 Cyanobacterial community composition analysis of salinity- and sulfate-manipulated microbial mats. (a) Cyanobacterial PCRdenaturing gradient gel electrophoresis analysis of composite samples of microbial mat cores $(0-5 \mathrm{~mm})$ taken at the start of the experiment (T0), after 4.5 months (T1) and after 11 months (T2) under high-salinity and high-sulfate conditions (85P), high-salinity and depleted sulfate conditions (85M), lowered salinity and high-sulfate conditions (35P), and lowered salinity and depleted sulfate conditions (35M). Two dominant bands ('A' and 'B') are indicated by arrows and represent cyanobacterial populations belonging to the Oscillatorian Cluster 5 and to Microcoleus chthonoplastes, respectively (as described in the text and shown in Figure 2). Bands excised and sequenced are indicated by boxes and labels (EB1-4, as described in the text). (b) Cluster analysis and the unweighted pair group method using arithmetic averages dendogram of the DGGE gel from (a). Nodes discussed in the text are indicated by a black circle and label. Dominant and excised bands are indicated by arrows and labels.

point (T2) were significantly different from all other samples and clustered together (node 'c'; Figure 1b). These samples were characterized by the presence of the population represented by the bands EB1 (T285M and T2-35M), EB3 (T2-85M) and EB4 (T2-35M).

\section{Comparison to previous molecular analyses of hypersaline microbial mats}

The cyanobacterial 16S rRNA genes recovered in this study (54 sequences from the general bacterial clone library and 13 from band excision and sequencing) were compared to other hypersaline microbial mat cyanobacteria by developing a large library of sequences recovered from other studies of moderately hypersaline microbial mats (Figure 2; Table 4). A total of 927 cyanobacteria sequences were retrieved from the GenBank database and aligned and inserted, together with the sequences recovered in this study, into a bacterial 16S rRNA gene tree of approximately 100000 sequences. Sequences other than those from cyanobacteria were subsequently removed. The resulting phylogenetic tree (Figure 2) was compressed into a number of clusters by visually identifying major groups of cyanobacteria that were primarily or entirely composed of microbial mat sequences. Overwhelmingly, most of the microbial mat cyanobacterial sequences were identified belonging to the order Oscillatoriales (filamentous and nonheterocystous). Greater than $75 \%$ of all the recovered microbial mat cyanobacterial sequences belonged to four major groups, indicated as 'Cluster 1,' 'Cluster 5,' 'Halothece/Cyanothece/Euhalothece,' and 'M. chthonoplastes.' Cluster 1 is comprised almost entirely of sequences (256 of 267) derived from Bahamian mats (Yannarell et al., 2006, 2007), and no sequences belonging to this cluster were detected in this study or that of Ley et al. (2006). Organisms belonging to this cluster were identified as uncultivated Salt Pond LPP (Lyngbya/Phormidium/Plectonema) and are likely capable of $\mathrm{N}_{2}$ fixation (Yannarell et al., 2007). Cyanobacteria from the Halothece/ Cyanothece/Euhalothece clade were important members of Bahamian mats, particularly after hurricane damage (Yannarell et al., 2007). These organisms were detected in Guerrero Negro mats by Ley et al. (2006), but only a single sequence of this clade was recovered in this study. Conversely, Oscillatorian cyanobacteria belonging to Cluster 5 were identified in this study ( 22 of 54 sequences), in that of Ley et al. (2006) (22 of 38 sequences), Yannarell et al. (2006) (156 of 373 sequences), Yannarell et al. (2007) (8 of 322 sequences) and from a study of Bahamian stromatolites (5 of 39 cyanobacterial sequences; DQ423810-DQ424817). Together with $M$. chthonoplastes, this was the most abundant cyanobacterial group detected in this study and was not significantly affected by salinity and sulfate manipulations. M. chthonoplastes sequences were a 
significant component of the cyanobacterial clone library generated in this study (24 of 54 sequences) and that of several other studies (Nübel et al., 2000; Abed and Garcia-Pichel, 2001; unpublished sequences DQ423810-DQ424817). However, almost no $M$. chthonoplastes sequences were recovered by Ley et al. (2006) (1 of 38 cyanobacterial sequences) or by Yannarell et al. (2006, 2007) (1 of 695 sequences).

The general bacterial clone library generated in this study (Table 3) was also compared to a larger general bacterial analysis of a microbial mat sampled from the same pond in Guerrero Negro (Baja, California Sur, Mexico) (Ley et al., 2006).

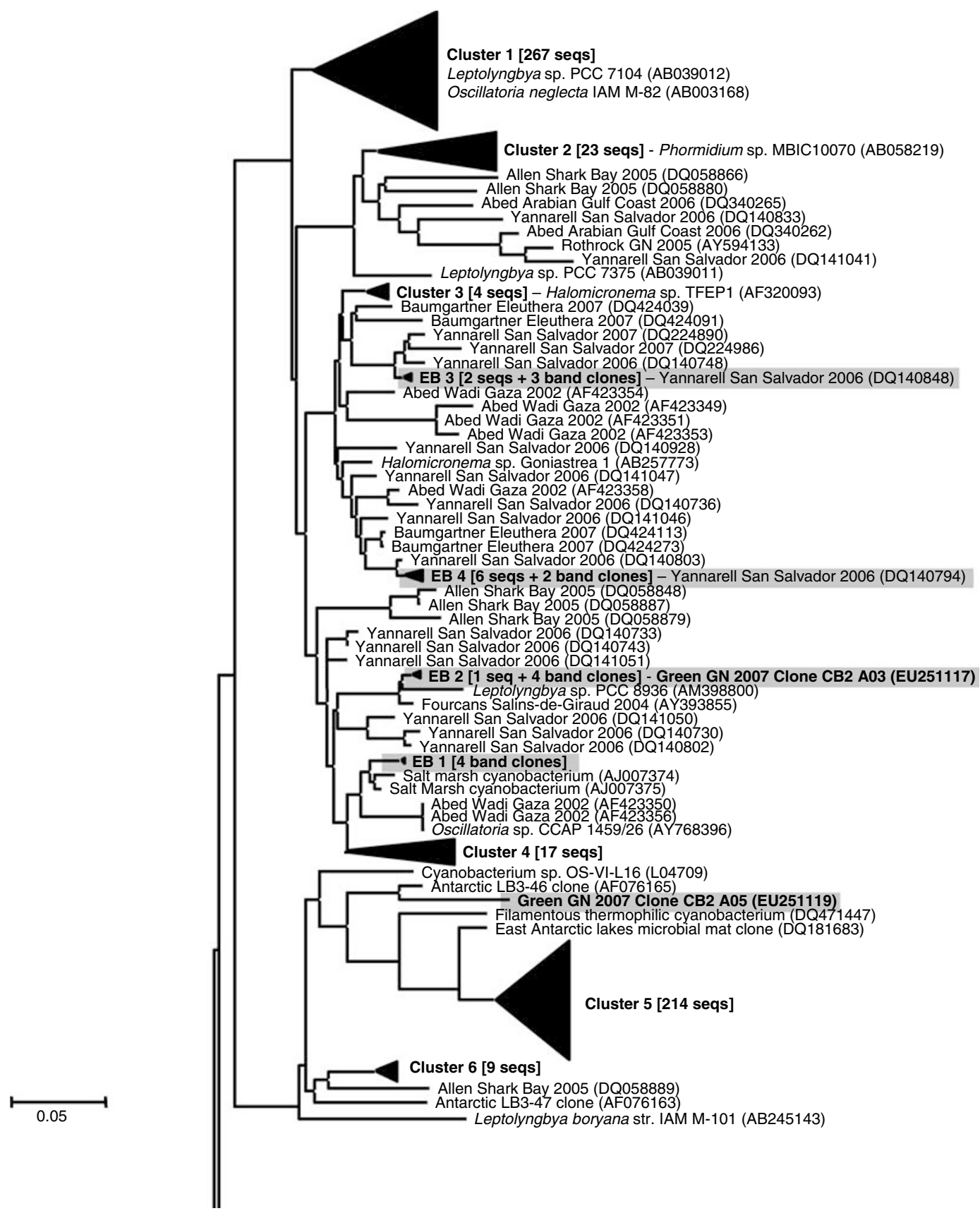

Figure 2 Phylogenetic tree of cyanobacterial 16S rRNA genes. Short cyanobacterial sequences recovered in this and other studies of hypersaline microbial mats were inserted into a near full-length rRNA gene tree within the phylogenetic software package ARB, as described in the text. Groups of sequences derived primarily from cultivation-independent analysis of hypersaline microbial mats have been compressed into a series of clusters (1-17). For each grouping, the number of environmental sequences contained within is provided in brackets and, if present, a representative isolate clustering within the clade is indicated. For environmental sequences grouping within well-established taxa of cyanobacteria, the compressed clades are labeled with a representative species or genus (for example, Microcoleus chthonoplastes). Environmental sequences that are not compressed into clusters or clades are indicated by author, microbial mat sampling location and year of submission to the GenBank database. Sequences from this study are also highlighted in gray. The scale bar represents 0.05 substitution per nucleotide position. 


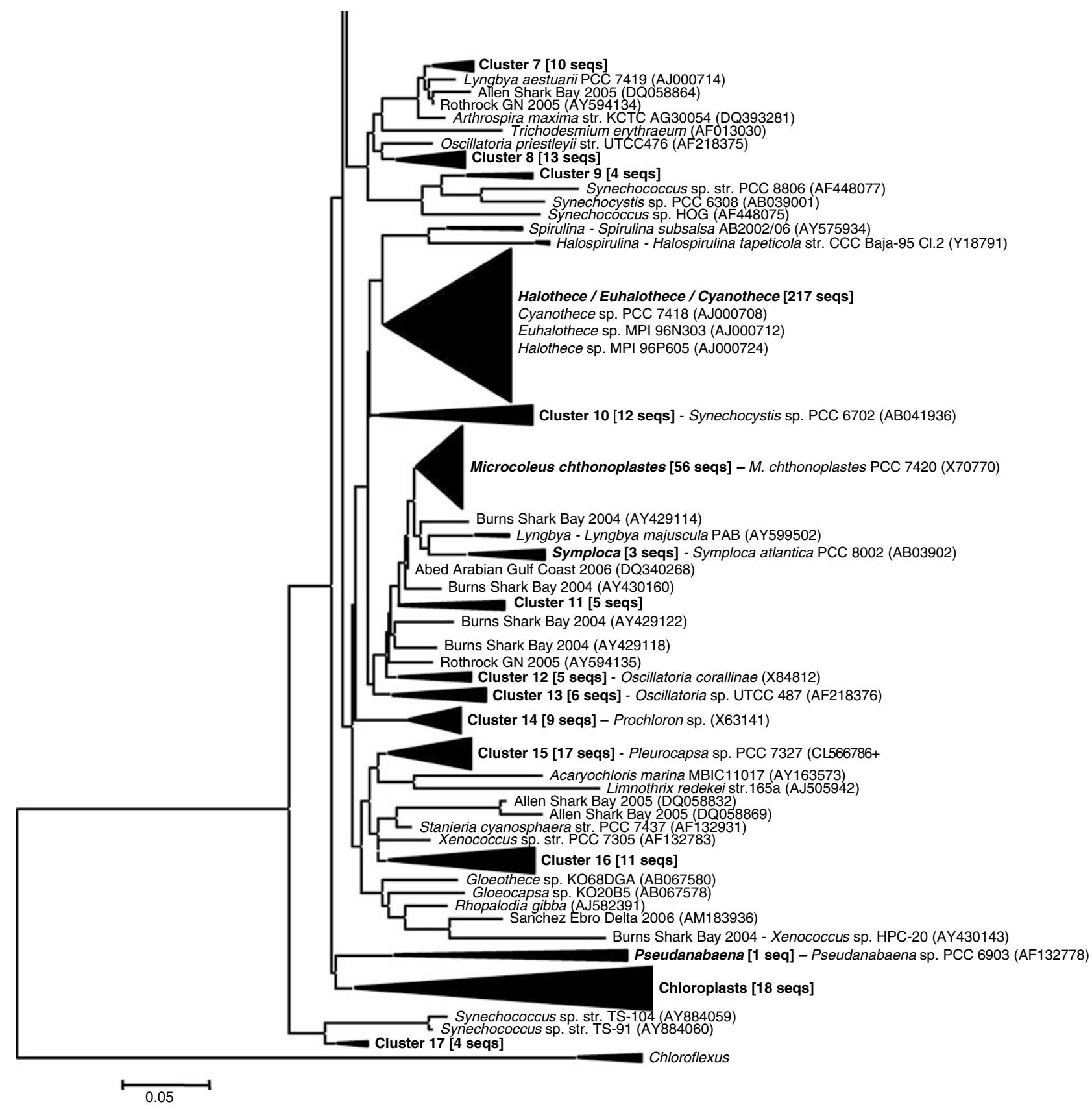

Figure 2 Continued.

In that study, nearly 1600 clones generated from 10 mat slices (to a depth of $60 \mathrm{~mm}$ ) were analyzed. Of those clones, 949 were recovered from $0-5 \mathrm{~mm}$ depths; their taxonomic affiliation is presented in Table 3. Apart from the discrepancy in abundance of cyanobacterial sequences, there were broad similarities in the general bacterial clone library between this study and that of Ley et al. (2006). Proteobacteria, Spirochetes, Bacteroidetes, Chloroflexi and Planctomycetes were the most abundant sequences recovered in the general bacterial analysis of these Guerrero Negro mats, comprising 63\% (this study) and $71 \%$ (Ley et al., 2006) of bacterial sequences.
Chloroflexi were observed to be substantially more abundant in the clone library of Ley et al. (2006), whereas Spirochetes were more abundant in the clone library from this study.

\section{Discussion}

Effect of salinity and sulfate manipulations on cyanobacteria

The study of microbial mats subject to salinity and sulfate manipulations has been a long-term effort at the NASA ARC. Decrease of sulfate concentration 
(below $1 \mathrm{mM}$ ) significantly impacts a variety of mat variables, including acetate concentration (significantly increased; Kelley et al., 2006), carbon isotope values of DIC and methane (significantly more positive; Bebout et al., 2004; Kelley et al., 2006), rates of sulfate reduction (significantly lowered; Bebout et al., 2004), rates of methanogenesis and concentrations of methane (significantly increased; Bebout et al., 2004; Kelley et al., 2006), and composition of mat methanogen community (development of novel, putative hydrogenotrophic methanogens; Smith et al., 2008). Decreased sulfate concentrations have not been shown, however, to significantly affect rates of oxygenic photosynthesis (Bebout et al., 2004).

Elsewhere, research into hypersaline microbial mats has indicated that salinity, often varying as a function of desiccation, is a crucial factor in shaping community structure (Garcia-Pichel et al., 1999; Nübel et al., 2000; Rothrock and Garcia-Pichel, 2005; Abed et al., 2007). Increased salinity can have a substantial negative impact on photosynthesis via direct and indirect effects, and truly dramatic decreases in gross photosynthesis begin above salinities of 100 p.p.t. (Garcia-Pichel et al., 1999). Conversely, Pinckney et al. (1995) and Paerl et al. (2003) found that hypersaline mats exposed to lower salinities in short-term incubations ( 2 to 5 days) demonstrated higher rates of $\mathrm{CO}_{2}$ and $\mathrm{N}_{2}$ fixation. In the study by Paerl et al. (2003), microscopic observations did not reveal substantial shifts in the cyanobacterial community composition, and the system was still dominated by cyanobacteria from the genera Microcoleus, Lyngbya, Schizothrix and Oscillatoria.

In this study, within the context of dramatic changes to the mat chemistry and microbiology (for example, lowered rates of sulfate reduction, increased abundance of hydrogenotrophic methanogens), the cyanobacterial community population composition in the surface of these hypersaline microbial mats was only modestly affected by the experimental manipulation of salinity and/or sulfate concentration, and the dominant cyanobacterial populations were unaffected. The relative abundance of cyanobacteria was not significantly affected by any of the manipulations. Interestingly, although the dominant populations remained the same, their apparent very fine scale distribution appeared to have been altered. Distinctive color, texture and vertical microbial population distribution changes (including $M$. chthonoplastes) were reproducibly observed as a function of the sulfate and salinity manipulations (L Prufert-Bebout et al., in preparation).

The stability of the cyanobacterial population during the dramatic shift in salinity does not reveal the physiological transitions that are likely to occur. Cyanobacteria respond to osmotic stress by the production of organic solutes, although the production of osmolytes is not necessarily burdensome. 
A number of studies have suggested that although microbial mats are highly productive, in some, little overall growth is seen as most of the organic matter is recycled within the mat (for example, via photorespiration) (Krumbein et al., 1977; Canfield and Des Marais, 1994; Nold and Ward, 1996). Thus, the synthesis of osmolytes may represent a reallocation of carbon within the cell, but it does not necessarily affect rates of oxygen evolution or uptake (Garcia-Pichel et al., 1999).

With a decrease in salinity, mat microorganisms can respond by excretion of the low molecular weight osmolytes potentially stimulating, temporarily, heterotrophic activity. For many of the Oscillatoriales, glucosylglycerol is the sole or primary organic solute, and some accumulate disaccharide as secondary solutes, for example, sucrose or trehalose (Stal and Reed, 1987). M. chthonoplastes, which produce glycosylglycerol and trehalose as osmolytes, appear to increase the relative proportion of trehalose under hyposaline conditions (Karsten, 1996). In addition, M. chthonoplastes can degrade and partially ferment glycosylglycerol (Moezelaar et al., 1996), a capability that may contribute to the dominance of $M$. chthonoplastes under a range of salinities.

The cyanobacterial community of the mat under native conditions was dominated by two cyanobacteria, the cosmopolitan cyanobacterium $M$. chthonoplastes and the uncultured Oscillatorian group of cyanobacteria shown to be representative in various hypersaline microbial mats ('Cluster 5'). The identification of a second, dominant filamentous cyanobacterial population in these and other hypersaline mats, in addition to $M$. chthonoplastes, is a key finding, but perhaps not surprising. Previous microscopic analyses of these and other microbial mats have revealed multiple different filamentous cyanobacteria (D'Amelio et al., 1989). Furthermore, these two populations were present and dominant in all samplings, regardless of treatment or time. This is in contrast to a similar microbial mat from Solar Lake (Sinai, Egypt), where long-term maintenance of transplanted microbial mats resulted in the disappearance of $M$. chthonoplastes (Abed and GarciaPichel, 2001). The stability of the cyanobacterial community structure is consistent with prior studies of NASA ARC greenhouse-maintained mats (Bebout et al., 2002) and is an essential result for conducting greenhouse experiments with these mat systems.

Although the mat community was dominated by two cyanobacterial populations, the PCR-denaturing gradient gel electrophoresis profiles revealed additional diversity that was not detected by direct sequencing of the bacterial clone library. Furthermore, a divergence in the cyanobacterial community composition was observed under low-sulfate treatments after nearly 1 year (T2 sampling). In the $35 \mathrm{M}$ and $85 \mathrm{M}$ treatments $(0.3$ and $0.9 \mathrm{mM}$ sulfate after 17 months, respectively), a number of cyanobacterial populations present in the initial sample were absent, while novel cyanobacteria were observed to develop. Four DGGE bands of interest, representing populations increasing in relative abundance under lowered salinity or sulfate conditions, were sequenced and the analyses of these sequences revealed that the representative organisms were closely related to environmental cyanobacterial from other hypersaline microbial mats. This finding suggests that cyanobacterial populations that could have been competitive at seawater salinities (that is, 35 p.p.t.) have not persisted under the long-term native, high-salinity conditions of these mats. The dominance of the M. chthonoplastes and Cluster 5 cyanobacterial populations in this study, and the development of only hypersaline cyanobacteria under the low-salinity and low-sulfate conditions may be an experimental construct reflecting the transition from restrictive (high salinity, high sulfate) to less restrictive conditions. This may also explain why acetoclastic methanogens, which are hypothetically absent from high-salinity environments (Oren, 1999), never developed to a level detectable by our analyses in the $35 \mathrm{M}$ treatment, even though the salinity dropped and acetate accumulated significantly (Kelley et al., 2006; Smith et al., 2008).

The dominance of $M$. chthonoplastes within the experimental system employed in this study, however, is consistent with the well-established strong competitive ability and great flexibility of these organisms. For example, M. chthonoplastes has been shown to grow under a salinity range of $0-12 \%$ (Garcia-Pichel et al., 1996; Karsten, 1996; Nübel et al., 2000). M. chthonoplastes has been shown to be a dominant member of the photosynthetic population in hypersaline mats from Guerrero Negro (Mexico; except where the salinity exceeds $12 \%$ ), Solar Lake Sinai (Egypt), Spencer Gulf and Shark Bay (Australia) and the Delta del Ebro, (Spain; reviewed in Garcia-Pichel et al., 1996; MartinezAlonso et al., 2004). A caveat, however; while M. chthonoplastes do grow over a broad range of salinities, Karsten (1996) demonstrated that M. chthonoplastes isolates from hypersaline environments grew better under hypersaline conditions, and in microbial mats from Limfjorden (Denmark) developing under lower salinities (23-29 p.p.t. salinity), M. chthonoplastes were not detected (Lassen et al., 1992). Nonetheless, here these factors do not appear to have been adequate to displace $M$. chthonoplastes as one of two dominant mat cyanobacterial populations.

While M. chthonoplastes has been well characterized, no close cultured relative is currently available for the Oscillatorian organisms of Cluster 5. These organisms, detected in a number of molecular analyses of microbial mats (Abed and Garcia-Pichel, 2001; Ley et al., 2006; Yannarell et al., 2006, 2007), also appear to persist under a range of salinities. Although the lack of a representative isolate of this group limits our ability to infer the capabilities and 
activities of these organisms, we note that higher resolution depth profiles of cyanobacterial populations in these mats revealed that the Cluster 5 organisms were primarily detected in the $0-2 \mathrm{~mm}$ region, while $M$. chthonoplastes was detected at all depths below $0.5 \mathrm{~mm}$ to a depth of $25 \mathrm{~mm}$ (data not shown). Interestingly, members of Cluster 5 were abundant in well-established mats from the Bahamas, but nearly absent from colonizing mats developing after hurricane damage (Yannarell et al., 2006, 2007), a finding that suggests that this group of organisms is associated with a climax community in hypersaline mats rather than with colonization.

Yannarell et al. (2007) identified the three dominant cyanobacteria in the Bahamian mats (including Cluster 5 organisms) as putatively being capable of $\mathrm{N}_{2}$ fixation (as evidenced by the presence of nifH genes consistent with the phylogeny of the recovered cyanobacterial 16S rRNA genes). Previous analysis of mats maintained under greenhouse conditions has indicated a slow depletion of fixed nitrogen over time due to the absence of external inputs available in the field and a resultant general increase in rates of $\mathrm{N}_{2}$ fixation (L Prufert-Bebout, unpublished data). This depletion does not appear to have altered the dominance of either Cluster 5 cyanobacteria, which are likely capable of nitrogen fixation, or M. chthonoplastes, which are not.

Cyanobacteria are dominant members of the microbial community in hypersaline mat systems

In this study, we sectioned the mats into rather crude fragments spanning the $0-5 \mathrm{~mm}$ depth range. This region includes the aerobic photic zone, the oxygen chemocline and a small portion of the constantly anaerobic, low-sulfide zone (Jorgensen et al., 1983; Revsbech et al., 1983; Frund and Cohen, 1992; Minz et al., 1999; Ley et al., 2006). In exploring the abundance of cyanobacteria within this region of the mat, we observed that cyanobacterial sequences comprised approximately $20 \%$ of the total bacterial clone library, a value roughly five times greater than that reported in a recent rRNA gene analysis of these microbial mat communities (Ley et al., 2006). In that prior study, cyanobacterial sequences comprised approximately $6 \%$ of the clone library in the 0-2 mm depths and $4 \%$ over the $0-5 \mathrm{~mm}$ depths-a depth range comparable to our current study (Ley et al., 2006). Despite a relatively low proportion of cyanobacterial rRNA gene sequences in their general bacterial clone library, Ley et al. (2006) showed that cyanobacterial rRNA accounted for $87 \%$ of total rRNA recovered from the top $2 \mathrm{~mm}$ and for $28 \%$ of total rRNA from the $2-6 \mathrm{~mm}$ depths. Thus, the cyanobacterial activity represents the greatest proportional abundance of microbial activity in the region of greatest overall activity, as the abundance of total rRNA has been shown to drop dramatically below the top 1 or $2 \mathrm{~mm}$ of these types of mats (Minz et al., 1999; Ley et al., 2006).
In addition to a much lower abundance of cyanobacteria in general, Ley et al. (2006) recovered only a single sequence representing $M$. chthonoplastes. This absence is surprising, as Microcoleus filaments have been shown to be abundant in hypersaline microbial mats from many different locations, and certainly in the Guerrero Negro mats (D'Amelio et al., 1989; Jorgensen et al., 1983; GarciaPichel et al., 1996; Nübel et al., 2000; Bebout et al., 2002; Fourcans et al., 2004; Martinez-Alonso et al., 2004). We attempted to determine if the primers employed in this study and that of Ley et al. (2006) could be responsible for the different cyanobacterial community composition. To do so, we performed PCR with one of the general bacterial primer sets described by Ley et al. (2006) (primers 8F(a) and 1391R; Table 1), with the primer set $8 \mathrm{~F} / 1492 \mathrm{R}$ used in this study and with the primer sets $8 \mathrm{~F} / 1391 \mathrm{R}$ and $8 \mathrm{~F}(\mathrm{a}) / 1492 \mathrm{R}$. These reactions were performed with a range of PCR annealing temperatures $\left(50-60^{\circ} \mathrm{C}\right)$ and PCR mix magnesium concentrations (1.5-4.0 mM). The general bacterial PCR products generated from these reactions were then subject to nested PCR with general bacterial and cyanobacterial primers for DGGE (341F/907R and CYA359F/CYA781R; Table 1). No significant differences in community composition, as revealed by DGGE, were observed (data not shown), indicating that the choice of PCR primer was not likely to be responsible for the absence of $M$. chthonoplastes sequences. We hypothesize that the difference may be a result of differing DNA extraction protocol. Two major differences in our extraction methods included the use of hexadecyltrimethylammonium bromide and potassium ethyl xanthogenate in the extraction buffer. Xanthogenate, a polysaccharide-solubilizing compound, has been shown to aid in the extraction of DNA from cyanobacteria (Tillett and Neilan, 2000). Alternatively, Bebout et al. (2002) reported the preferential degradation of $M$. chthonoplastes DNA upon multiple freezing and thawings of mat samples prior to DNA extraction, and we have observed a similar phenomenon with long-term storage of microbial mat DNA extracts (data not shown). Finally, we note that the differences could also reflect different sampling times and seasonal variations between this study and that of Ley et al. (2006).

Regardless of the cause, the low recovery of $M$. chthonoplastes rRNA genes from the Guerrero Negro mats most likely enabled Ley et al. (2006) to reveal additional microbial diversity in the mat by circumventing a dominant, but known, DNA template in the molecular analysis. For a clone library of a given size, the low recovery of a dominant template will allow the detection of more minor microbial populations (Green and Minz, 2005). The low recovery of $M$. chthonoplastes DNA may have been important throughout the mat and not just near the surface. Cyanobacteria, including $M$. chthonoplastes, have been detected below the surface of these and other microbial mats, to a depth 
of over $14 \mathrm{~mm}$ (D Minz, personal communication; Jorgensen et al., 1988).

\section{Cyanobacteria in hypersaline microbial mats}

A highly diverse community of cyanobacteria, overwhelmingly filamentous and of the order Oscillatoriales, have been detected in hypersaline microbial mats by cultivation-independent molecular techniques. In generating a single phylogenetic tree with nearly 1000 cyanobacterial 16S rRNA gene sequences from multiple hypersaline microbial mats studies, we observed that there were many groups of cyanobacteria composed entirely or nearly so of cyanobacteria from hypersaline microbial mats. Furthermore, in many cases no closely related cyanobacterial isolates are available for comparison to environmental sequences. A number of major groups of hypersaline microbial mat cyanobacteria were identified (that is, clusters with greater than 200 sequences), but this should be taken with the caveat that the available sequence information is heavily weighted by the relatively large clones libraries generated by Yannarell et al. $(2006,2007)$ from Bahamian mats. The dominance of filamentous cyanobacteria in these hypersaline mat systems is not unexpected; these organisms, via production of sheath material, are largely responsible for the thick mat texture found in these systems (Stal et al., 1985; D'Amelio et al., 1989). At even higher salinities, unicellular cyanobacteria, such as Halothece or Euhalothece, can predominate (Nübel et al., 2000; Sorensen et al., 2004). Heterocystous cyanobacteria appear to be entirely absent from submerged hypersaline microbial mats a possible result of sulfide sensitivity (Stal, 1995). In this study, even in the experimental treatments with lowered sulfate (with resultant lower sulfate-reduction rates and lower sulfide concentrations; Bebout et al., 2004), heterocystous cyanobacteria were never detected.

In this study, we demonstrate that two groups of Oscillatorian cyanobacteria, including M. chthonoplastes, predominate in microbial mats subject to dramatic shifts in sulfate and salinity over the course of a year. The relative abundance of cyanobacteria in the surface of these mats, roughly $20 \%$ of the bacterial community as assayed by molecular techniques, was not significantly affected by salinity or sulfate manipulations. Overall, these hypersaline mats are shown to have highly stable cyanobacterial populations capable of persisting under a wide range of environmental conditions.

\section{Acknowledgements}

We acknowledge the Exportadora de Sal of Guerrero Negro (Baja California Sur, Mexico), for access to sites, Brad M Bebout for the development and maintenance of the microbial mat greenhouses and flow systems, Ruth Ley in providing an ARB database containing rRNA gene sequences from her study, Mary Hogan for laboratory assistance, Marilyn Vogel for assistance with statistical analyses and Erich Fleming for comments on the paper. Stefan Green was funded by a fellowship from the National Research Council and from the Oak Ridge Associated Universities postdoctoral fellowship program. Experimental operations, sequencing, molecular and technical assistance were supported by a grant to Lee Prufert-Bebout through the NASA Biomolecular Systems Research Program, and use of the molecular analysis facility was provided through Exobiology funding programs.

\section{References}

Abed RM, Al-Thukair A, de Beer D. (2006). Bacterial diversity of a cyanobacterial mat degrading petroleum compounds at elevated salinities and temperatures. FEMS Microbiol Ecol 57: 290-301.

Abed RM, Garcia-Pichel F. (2001). Long-term compositional changes after transplant in a microbial mat cyanobacterial community revealed using a polyphasic approach. Environ Microbiol 3: 53-62.

Abed RM, Kohls K, de Beer D. (2007). Effect of salinity changes on the bacterial diversity, photosynthesis and oxygen consumption of cyanobacterial mats from an intertidal flat of the Arabian Gulf. Environ Microbiol 9: 1384-1392.

Abed RM, Safi NM, Koster J, de Beer D, El-Nahhal Y, Rullkotter J et al. (2002). Microbial diversity of a heavily polluted microbial mat and its community changes following degradation of petroleum compounds. Appl Environ Microbiol 68: 1674-1683.

Aizenshtat Z, Lipiner G, Cohen Y. (1984). Biogeochemistry of carbon and sulfur in the microbial mats of the Solar Lake (Sinai). In: Cohen Y, Castenholz RW, Halvorson HO (eds). Microbial Mats: Stromatolites. Alan R Liss Inc.: New York. pp 281-312.

Altschul SF, Madden TL, Schaffer AA, Zhang J, Zhang Z, Miller W et al. (1997). Gapped BLAST and PSI-BLAST: a new generation of protein database search programs. Nucleic Acids Res 25: 3389-3402.

Awramik SM. (1984). Ancient stromatolites and microbial mats. In: Cohen Y, Castenholz RW, Halvorson HO (eds). Microbial Mats: Stromatolites. Alan R Liss Inc.: New York. pp 1-22.

Bebout BM, Carpenter SP, Des Marais DJ, Discipulo M, Embaye T, Garcia-Pichel F et al. (2002). Long-term manipulations of intact microbial mat communities in a greenhouse collaboratory: simulating earth's present and past field environments. Astrobiology 2: 383-402.

Bebout BM, Hoehler TM, Thamdrup B, Albert D, Carpenter SP, Hogan M et al. (2004). Methane production by microbial mats under low sulphate concentrations. Geobiology 2: 87-96.

Burns BP, Goh F, Allen M, Neilan BA. (2004). Microbial diversity of extant stromatolites in the hypersaline environment of Shark Bay, Australia. Environ Microbiol 6: 1096-1101.

Canfield DE, Des Marais DJ. (1991). Aerobic sulfate reduction in microbial mats. Science 251: 1471-1473.

Canfield DE, Des Marais DJ. (1994). Cycling of carbon, sulfur, oxygen and nutrients in a microbial mat. In: Stal LJ, Caumette P (eds). Microbial Mats: Structure, Development and Environmental Significance. Springer-Verlag: Berlin. pp 255-264.

Canfield DE, Habicht KS, Thamdrup B. (2000). The Archean sulfur cycle and the early history of atmospheric oxygen. Science 288: 658-661. 
Canfield DE, Teske A. (1996). Late Proterozoic rise in atmospheric oxygen concentration inferred from phylogenetic and sulphur-isotope studies. Nature 382: 127-132.

Cohen Y, Jorgensen BB, Revsbech NP, Poplawski R. (1986). Adaptation to hydrogen sulfide of oxygenic and anoxygenic photosynthesis among cyanobacteria. Appl Environ Microbiol 51: 398-407.

Cole JR, Chai B, Farris RJ, Wang Q, Kulam-Syed-Mohideen AS, McGarrell DM et al. (2007). The ribosomal database project (RDP-II): introducing myRDP space and quality controlled public data. Nucleic Acids Res 35: D169-D172.

D’Amelio ED, Cohen Y, Des Marais DJ. (1989). Comparative functional ultrastructure of two hypersaline submerged cyanobacterial mats: Guerrero Negro, Baja California Sur, Mexico and Solar Lake, Sinai, Egypt. In: Cohen Y, Rosenberg E (eds). Microbial Mats: Physiological Ecology of Benthic Microbial Communities. American Society for Microbiology: Washington, DC. pp 97-113.

de Wit R, van Gemerden H. (1987). Oxidation of sulfide to thiosulfate by Microcoleus chthonoplastes. FEMS Microbiol Lett 45: 7-13.

DeSantis Jr TZ, Hugenholtz P, Keller K, Brodie EL, Larsen N, Piceno YM et al. (2006a). NAST: a multiple sequence alignment server for comparative analysis of $16 \mathrm{~S}$ rRNA genes. Nucleic Acids Res 34: W394-W399.

DeSantis TZ, Hugenholtz P, Larsen N, Rojas M, Brodie EL, Keller K et al. (2006b). Greengenes, a chimera-checked $16 \mathrm{~S}$ rRNA gene database and workbench compatible with ARB. Appl Environ Microbiol 72: 5069-5072.

Fourcans A, de Oteyza TG, Wieland A, Sole A, Diestra E, van Bleijswijk J et al. (2004). Characterization of functional bacterial groups in a hypersaline microbial mat community (Salins-de-Giraud, Camargue, France). FEMS Microbiol Ecol 51: 55-70.

Frund C, Cohen Y. (1992). Diurnal cycles of sulfate reduction under oxic conditions in cyanobacterial mats. Appl Environ Microbiol 58: 70-77.

Garcia-Pichel F, Kuhl M, Nübel U, Muyzer G. (1999). Salinity-dependent limitation of photosynthesis and oxygen exchange in microbial mats. J Phycol 35: $227-238$

Garcia-Pichel F, Prufert-Bebout L, Muyzer G. (1996). Phenotypic and phylogenetic analyses show Microcoleus chthonoplastes to be a cosmopolitan cyanobacterium. Appl Environ Microbiol 62: 3284-3291.

Green SJ, Michel Jr FC, Hadar Y, Minz D. (2004). Similarity of bacterial communities in sawdust- and strawamended cow manure composts. FEMS Microbiol Lett 233: $115-123$.

Green SJ, Minz D. (2005). Suicide polymerase endonuclease restriction, a novel technique for enhancing PCR amplification of minor DNA templates. Appl Environ Microbiol 71: 4721-4727.

Habicht KS, Gade M, Thamdrup B, Berg P, Canfield DE. (2002). Calibration of sulfate levels in the Archean ocean. Science 298: 2372-2374.

Huber T, Faulkner G, Hugenholtz P. (2004). Bellerophon: a program to detect chimeric sequences in multiple sequence alignments. Bioinformatics 20: 2317-2319.

Jorgensen BB. (1982). Mineralization of organic matter in the sea bed-the role of sulfate reduction. Nature 296: $643-645$.

Jorgensen BB, Cohen Y, Revsbech NP. (1986). Transition from anoxygenic to oxygenic photosynthesis in a
Microcoleus chthonoplastes cyanobacterial mat. Appl Environ Microbiol 51: 408-417.

Jorgensen BB, Cohen Y, Revsbech NP. (1988). Photosynthetic potential and light-dependent oxygen consumption in a benthic cyanobacterial mat. Appl Environ Microbiol 54: 176-182.

Jorgensen BB, Revsbech NP, Cohen Y. (1983). Photosynthesis and structure of benthic microbial mats: microelectrode and SEM studies of four cyanobacterial communities. Limnol Oceanogr 28: 1075-1093.

Karsten U. (1996). Growth and organic osmolytes of geographically different isolates of Microcoleus chthonoplastes (Cyanobacteria) from benthic microbial mats: response to salinity change. J Phycol 32: 501-506.

Kelley CA, Prufert-Bebout L, Bebout BM. (2006). Changes in carbon cycling ascertained by stable isotopic analyses in a hypersaline microbial mat. J Geophys Res 111: G04012.

Krumbein WE, Cohen Y, Shilo M. (1977). Solar Lake (Sinai). 4. Stromatolitic cyanobacterial mats. Limnol Oceanogr 22: 635-656.

Lane DJ. (1991). 16S/23S rRNA sequencing. In: Stackebrandt E, Goodfellow M (eds). Nucleic Acid Techniques in Bacterial Systematics. John Wiley \& Sons: Chichester, England. pp 115-147.

Lassen C, Ploug H, Jorgensen BB. (1992). Microalgal photosynthesis and spectral scalar irradiance in coastal marine sediments of Limfjorden, Denmark. Limnol Oceanogr 37: 760-772.

Ley RE, Harris JK, Wilcox J, Spear JR, Miller SR, Bebout BM et al. (2006). Unexpected diversity and complexity of the Guerrero Negro hypersaline microbial mat. Appl Environ Microbiol 72: 3685-3695.

Ludwig W, Strunk O, Westram R, Richter L, Meier H, Kumar Y et al. (2004). ARB: a software environment for sequence data. Nucleic Acids Res 32: 1363-1371.

Martinez-Alonso M, Mir J, Caumette P, Gaju N, Guerrero R, Esteve I. (2004). Distribution of phototrophic populations and primary production in a microbial mat from the Ebro Delta, Spain. Int Microbiol 7: 19-25.

Minz D, Fishbain S, Green SJ, Muyzer G, Cohen Y, Rittmann BE et al. (1999). Unexpected population distribution in a microbial mat community: sulfatereducing bacteria localized to the highly oxic chemocline in contrast to a eukaryotic preference for anoxia. Appl Environ Microbiol 65: 4659-4665.

Moezelaar R, Bijvank SM, Stal LJ. (1996). Fermentation and sulfur reduction in the mat-building cyanobacterium Microcoleus chthonoplastes. Appl Environ Microbiol 62: 1752-1758.

Muyzer G, de Waal EC, Uitterlinden AG. (1993). Profiling of complex microbial populations by denaturing gradient gel electrophoresis analysis of polymerase chain reaction-amplified genes coding for $16 \mathrm{~S}$ rRNA. Appl Environ Microbiol 59: 695-700.

Muyzer G, Smalla K. (1998). Application of denaturing gradient gel electrophoresis (DGGE) and temperature gradient gel electrophoresis (TGGE) in microbial ecology. Antonie Van Leeuwenhoek 73: 127-141.

Nold SC, Ward DM. (1996). Photosynthate partitioning and fermentation in hot springs microbial mat communities. Appl Environ Microbiol 62: 4598-4607.

Nübel U, Garcia-Pichel F, Clavero E, Muyzer G. (2000). Matching molecular diversity and ecophysiology of benthic cyanobacteria and diatoms in communities along a salinity gradient. Environ Microbiol 2: $217-226$ 
Nübel U, Garcia-Pichel F, Muyzer G. (1997). PCR primers to amplify $16 \mathrm{~S}$ rRNA genes from cyanobacteria. Appl Environ Microbiol 63: 3327-3332.

Oren A. (1999). Bioenergetic aspects of halophilism. Microbiol Mol Biol Rev 63: 334-348.

Paerl HW, Steppe TF, Buchan KC, Potts M. (2003). Hypersaline cyanobacterial mats as indicators of elevated tropical hurricane activity and associated climate change. Ambio 32: 87-90.

Pavlov AA, Kasting JF. (2002). Mass-independent fractionation of sulfur isotopes in Archean sediments: strong evidence for an anoxic Archean atmosphere. Astrobiology 2: 27-41.

Pinckney J, Paerl HW, Bebout BM. (1995). Salinity control of benthic microbial mat community production in a Bahamian hypersaline lagoon. J Exp Mar Biol Ecol 187: 223-237.

Revsbech NP, Jorgensen BB, Blackburn TH, Cohen Y. (1983). Microelectrode studies of the photosynthesis and $\mathrm{O}_{2}, \mathrm{H}_{2} \mathrm{~S}$ and $\mathrm{pH}$ profiles of a microbial mat. Limnol Oceanogr 28: 1062-1074.

Rothrock Jr MJ, Garcia-Pichel F. (2005). Microbial diversity of benthic mats along a tidal desiccation gradient. Environ Microbiol 7: 593-601.

Sigler WV, Bachofen R, Zeyer J. (2003). Molecular characterization of endolithic cyanobacteria inhabiting exposed dolomite in central Switzerland. Environ Microbiol 5: 618-627.

Smith JS, Green SJ, Kelley CA, Prufert-Bebout L, Bebout BM. (2008). Shifts in methanogen community structure and function associated with long-term manipulation of sulfate and salinity in a hypersaline microbial mat. Environ Microbiol 10: 386-394.

Sorensen KB, Canfield DE, Oren A. (2004). Salinity responses of benthic microbial communities in a solar saltern (Eilat, Israel). Appl Environ Microbiol 70: 1608-1616.

Stal LJ. (1995). Physiological ecology of cyanobacteria in microbial mats and other communities. New Phytol 131: $1-32$

Stal LJ, Reed RH. (1987). Low-molecular mass carbohydrate accumulation in cyanobacteria from a marine microbial mat in response to salt. FEMS Microbiol Ecol 45: 305-312.

Stal LJ, van Gemerden H, Krumbein WE. (1985). Structure and development of a benthic marine microbial mat. FEMS Microbiol Ecol 31: 111-125.

Tillett D, Neilan BA. (2000). Xanthogenate nucleic acid isolation from cultured and environmental cyanobacteria. J Phycol 36: 251-258.

Yannarell AC, Steppe TF, Paerl HW. (2006). Genetic variance in the composition of two functional groups (diazotrophs and cyanobacteria) from a hypersaline microbial mat. Appl Environ Microbiol 72: 1207-1217.

Yannarell AC, Steppe TF, Paerl HW. (2007). Disturbance and recovery of microbial community structure and function following Hurricane Frances. Environ Microbiol 9: 576-583.

Zhou J, Bruns MA, Tiedje JM. (1996). DNA recovery from soils of diverse composition. Appl Environ Microbiol 62: $316-322$. 